\title{
Effect of Cow Start Bolus Supplementation on Early Lactation Health and Performance Indicators in a Group of Older, At-Risk Dairy Cows
}

\author{
John Lawlor ${ }^{1,}$ ", Rachel Reardon ${ }^{1}$, Cathal O'Sé ${ }^{2}$, Enda Neville ${ }^{3}$, Alan Fahey ${ }^{3}$ \\ ${ }^{1}$ Anchor Life Science Ltd., Co. Cork, Ireland \\ ${ }^{2}$ Reprovet Ltd., Co. Cork, Ireland \\ ${ }^{3}$ School of Agriculture and Food Science, University College Dublin, Dublin, Ireland
}

Email address:

john.lawlor@anchorlifescience.com (J. Lawlor)

${ }^{*}$ Corresponding author

\section{To cite this article:}

John Lawlor, Rachel Reardon, Cathal O’Sé, Enda Neville, Alan Fahey. Effect of Cow Start Bolus Supplementation on Early Lactation Health and Performance Indicators in a Group of Older, At-Risk Dairy Cows. Animal and Veterinary Sciences. Vol. 9, No. 5, 2021 , pp. $134-140$. doi: 10.11648/j.avs.20210905.12

Received: September 9, 2021; Accepted: September 24, 2021; Published: October 5, 2021

\begin{abstract}
Whilst older cows can be some of the most profitable producers on the farm, as well as helping to reduce the environmental impact of dairy production and improving consumer perception of dairy farming, they can also be more prone to early lactation metabolic challenges and at higher risk of culling or death in early lactation. Research into nutritional supplementation strategies specifically to support older, at-risk herd members has not, to the author's knowledge, been carried out and leaves a dearth of knowledge as to how best to support the successful transition of this valuable cohort of cows from gestation into peak lactation. The objective of this study was to evaluate the effect of supplementation with a combined calcium, magnesium and antioxidant bolus (Cow Start) on key early lactation health and performance indicators in a cohort of older, higher yielding dairy cows that may be expected to be at greater risk of developing key post-partum metabolic disorders. High yielding multiparous $(\mathrm{n}=38)$ cows averaging 4.7 lactations at calving were enrolled in this study and randomly assigned to either a control $(\mathrm{CON}, \mathrm{n}=19)$ group or a Cow Start oral bolus supplemented $(\mathrm{CSC}, \mathrm{n}=19)$ group. The CON group experienced a clinical milk fever (Blood $\mathrm{Ca}<1.5 \mathrm{mM}$ ) incidence rate of $15.7 \%$ compared to $0 \%$ for the CSC group. Cows in the CSC group recorded a treatment effect of a significantly $(\mathrm{P}<0.01)$ higher blood calcium status compared to CON. Energy Corrected Milk volumes showed a statistical trend of an increase $(\mathrm{P}<0.10)$ from day 5 until day 60 of lactation for the CSC group $(+1.8 \mathrm{~kg} /$ day $)$ when compared to $\mathrm{CON}$, also milk fat $\mathrm{kg}(\mathrm{P}<0.05)$ and combined fat and protein $\mathrm{kg}$ yields $(\mathrm{P}<0.10)$ were increased in the CSC group when compared to the CON group. Results of this study suggest that supplementation of older at-risk cows with a combined calcium, magnesium and antioxidant (Cow Start) oral bolus can reduce the incidence rate of clinical milk fever and exposure to sub-clinical milk fever, whilst also improving blood calcium status and increasing milk production parameters in early lactation when compared to $\mathrm{CON}$.
\end{abstract}

Keywords: Calcium and Antioxidant Bolus, Post-Partum Calcium Status, Early Lactation At-Risk Cows

\section{Introduction}

Increased dairy cow longevity can be a key driver of farm profitability and it can also have a positive impact on reducing greenhouse gas emissions and can help to improve consumer perception of dairy farming as it can be seen as an indicator of animal welfare [1]. After milk yield, longevity is the second most important economic trait in dairy cows [2].
Average lifetime production in many progressive dairy countries averages at only 3.2 lactations, yet recent studies have shown that it can be halfway through the $2^{\text {nd }}$ lactation or even into the $3^{\text {rd }}$ lactation before replacement heifers reach a breakeven point and cover their rearing costs [3-5].

Whilst older cows can be some of the most profitable producers on the farm, older cows can be more prone to early lactation metabolic challenges and at higher risk of culling or 
death in early lactation compared to their younger herd mates $[6,7]$. Reinhardt (2011) showed that $2^{\text {nd }}$ lactation cows had a $4 \%$ risk of clinical milk fever which rose to $13 \%$ by the $6^{\text {th }}$ lactation, whilst the risk of sub-clinical milk fever was in the $41 \%$ to $54 \%$ range from lactations 2 to 6 [8]. In 2018, Probo et al. found that milk fever was the most influential disease associated with the risk of culling within the first 120 days in milk and this finding was previously seen by Seifi $[6,9]$.

At calving, the cow is faced with a sudden surge in calcium demand to support colostrum production. The ability of the cow to match this increased calcium demand with sufficient supply can be delayed by $24-48$ hours, as homeostatic mechanisms cannot upregulate calcium metabolism from the digestive or skeletal systems quickly enough [7]. It is this time lag between the sudden increase in calcium demand and the delay in calcium supply that can cause a deterioration in the cow's blood calcium status, which results in the cow developing a clinical milk fever (Blood $\mathrm{Ca}<1.5 \mathrm{mM}$ ) or sub-clinical milk fever (Blood $\mathrm{Ca}$ $\geq 1.5 \mathrm{mM}$ and $\leq 2.0 \mathrm{mM}$ ) [10].

Various studies have now proven that the incident rate of clinical milk fever can vary between $5-7 \%$ in dairy herds $[7,8]$, and that each case of clinical milk fever costs an average of US $\$ 250[7,11,12]$. Although less costly at $\$ 125$ per case, sub-clinical milk fever carries a much greater herdwide cost as the prevalence of sub-clinical milk fever is much greater in herds, with recorded incidence rates of $50 \%$ in multiparous cows [8]. On an annual basis, sub-clinical milk fever can represent $80 \%$ of the total costs of milk fever.

Calcium plays a critical role to the transitioning cow and its effect is broad based, as calcium plays an important role in a number of key areas for the cow in transition, from muscle and nerve function, to the physical barriers of the innate immune response and also the phagocytic response [13-16]. In 2011, Reinhardt demonstrated that normo-calcaemic cows $(\mathrm{Ca}>2.0 \mathrm{mM})$ had a lower serum non-esterified fatty acid (NEFA) levels postpartum than sub-clinical milk fever cows $(\mathrm{Ca}<2.0 \mathrm{mM}, \quad(\mathrm{P}<0.001)$ [8]. This result indicates that normocalcaemic cows are in better energy balance than the sub-clinical group. Whiteford and Sheldon (2005) demonstrated that cows with clinical milk fever had a greater number of endometritis cases $(\mathrm{P}<0.05)$ when compared to normo-calcaemic cows [17]. These findings were further supported by Martinez (2012) who found that cows that were in the sub-clinical milk fever range were 3.24 times more likely to develop metritis compared with normo-calcaemic cows $(\mathrm{P}<0.01$ [13].

It is clear from this recent research that there are significant health and performance gains to be obtained from trying to keep freshly calved, older at-risk cows in the normo-calcaemic range $(\mathrm{Ca}>2.0 \mathrm{mM})$ in the critical first hours after calving. Calcium status is not the only challenge that the transitioning cow faces, as demand for energy and antioxidants also surge in the first hours and days postpartum. Reduced dry matter intakes (DMI) in freshly calved cows often results in a reduction in supply of these nutrients to the cow and this can compromise her energy, mineral and antioxidant status [14].

Magnesium plays two critical roles in supporting calcium metabolism: firstly by reducing parathyroid hormone (PTH) secretion in response to hypocalcaemia and secondly by reducing the sensitivity of tissues to PTH [18, 19]. High levels of dietary potassium can have a negative effect on magnesium status and lead to hypomagnesemia which can then increase the risk of milk fever [7]. The Cow Start bolus includes rumen soluble magnesium in order to ensure adequate bioavailability of calcium and an optimally functioning calcium metabolism.

Vitamin E and selenium are also supplied in the Cow Start bolus as an aid to the immune response. Dietary antioxidants, notably vitamin $\mathrm{E}$ and selenium are important for their ability to neutralise reactive oxygen species and prevent periparturient diseases and reduce inflammation [20, 21]. Vitamin E plasma concentrations are lowest between one week pre-partum and two weeks post-partum, inadequate dietary vitamin $\mathrm{E}$ or selenium decreases neutrophil function during the peri-parturient period [22]. Decreased phagocytosis and intracellular killing by neutrophils occur in parallel with decreased DMI and decreased circulating vitamin E ( $\alpha$-tocopherol) concentration [23].

This realisation amongst veterinarians and dairy farmers of the hidden costs and prevalence of sub-clinical milk fever has led to an increase in the pro-phylactic use of oral calcium supplements in dairy cows thought of as being at higher risk of milk fever or early lactation metabolic diseases such as; retained placenta, metritis, endo-metritis, displaced abomasum or ketosis. Calcium supplements come in many forms such as calcium borogluconate for parenteral administration, or forms for oral administration such as; calcium boluses, drenches, pastes and drinks.

Whilst numerous published studies show a benefit to calcium status from oral calcium supplementation in a general population of cows, generally defined as second lactation and older, few studies have looked at the benefits of calcium supplementation in a narrow group of cows defined as being at higher risk of milk fever [24-27]. Also, few studies have demonstrated the benefit of oral calcium supplementation on key health indicators other than calcium status such as; risk of post-partum metabolic disease, energy status and milk production performance. Oeztzel and Miller (2012) found that cows that were both lame and had above average milk production levels ( $>5 \%$ above herd average) responded to supplementation by means of higher milk production levels [24]. Previous studies on a combined calcium, magnesium and antioxidant bolus (Cow Start) demonstrated a benefit in early lactation performance in terms of fewer metabolic issues (milk fever, retained placenta and uterine infections), significantly improved energy status and significantly improved milk production when compared to control and calcium only supplement groups [28, 29].

We hypothesise that the enhanced specification of the bolus will prove effective at helping the cohort of older and higher yielding cows that may be expected to be at higher 
risk of milk fever to transition into lactation with fewer metabolic challenges and as a result, produce more milk in the early lactation phase.

The objective of our study was to determine if supplementation with a combined calcium, magnesium and antioxidant bolus (Cow Start) of older, at-risk cows at calving would improve their blood calcium status and thereby reducing their risk to metabolic challenges while maintaining or improving milk, fat and protein production.

\section{Materials and Methods}

\subsection{Study Population}

The study was conducted over a 7-week calving period in a spring calving dairy herd in Ireland. The herd consisted of 220 higher yielding dairy cows with an average $305 \mathrm{~d}$ lactation yield of $8,242 \mathrm{~kg}$, produced from a predominantly grass based diet. Cows were required to have had a previous full-term pregnancy with valid on-farm records. Only second lactation and greater parity cows were eligible for the trial. The cows were blocked by parity and were randomly assigned to a control group (CON) or Cow Start (CSC) bolus group.

Table 1. Cow Age and Production Profile.

\begin{tabular}{lll}
\hline Treatment & CON & CSC \\
\hline $\mathrm{n}$ & 19 & 19 \\
Age (average lactation at calving) & 4.7 & 4.7 \\
Prev. Lact. 305 d Yield (Kg) & 8,711 & 8,956 \\
\hline
\end{tabular}

\subsection{Study Intervention}

38 multiparous cows took part in the study, 19 cows were enrolled in the CON group which received no bolus after calving and 19 cows were allocated to the CSC group which received two oral boluses. The first bolus was administered on the point of calving while the second bolus was given 12 hours later. Each CSC bolus contained $65 \mathrm{~g}$ of calcium (Seaweed derived calcium and calcium chloride), which delivers $50 \%$ more calcium than other commercially available calcium boluses, it also contains $4 \mathrm{~g}$ of rumen soluble magnesium. Vitamin $\mathrm{E}$ and selenium are also supplied in a rumen protected form (calcified fat matrix) as an aid in supporting the immune response.

\subsection{Production Data Recording}

All bolus administration, metabolic diseases and calving events were monitored and recorded by farm personnel. Milk samples were taken by an employee of the national milk recording programme. The samples were then sent to an independent accredited laboratory to analyse the milk composition of each milk sample including fat and protein percentage and the somatic cell count present in the sample from each cow. Milk yield was measured by the digital milk meters in the milking parlour for each cow for every milking and this was recorded by the Dairymaster Milk Manager software system. Daily milk volume data was obtained from this software for each cow for the first 60 days in milk (DIM).

\subsection{Sample Collection and Analysis}

Blood calcium records were provided by the farm vet from pre-existing farm health records. All blood procedures were overseen by the farm vet. Whole blood samples were taken from the coccygeal vein and immediately refrigerated at $4^{\circ} \mathrm{C}$ on the farm. Serum was separated for 5 minutes at $12,000 \mathrm{rpm}$ within 24 hours of the sample being taken, then labelled and frozen immediately. Samples were thawed at room temperature and analysed in batches using an IDEXX Catalyst chemistry analyser. The samples were taken at $0,1,4$ and 8 hours relative to the treatment with time 0 denoting the point of calving before the first bolus was administered.

\subsection{Statistical Analysis}

Data were analysed using SAS v9.4. All data residuals were checked for the assumptions of normality. The milk production parameters and daily milk yield data were analysed using the MIXED procedure. For the milk production parameters, parity, treatment (Control or CSC), and parity by treatment interaction were included as fixed effects and the previous 305-day milk production parameter were included as a covariate in the analysis. When analysing daily milk yield parity, treatment, days in milk (DIM) and the interactions between treatment and lactation and treatment and DIM were included as fixed effects. The previous 305day milk production parameter were included as a covariate in the analysis. Individual cow was considered as the experimental unit and included in the model as a random effect. Days in milk was used to model repeated measures using the appropriate (co)variance structure as determined by the lowest Bayesian Information Criterion.

Calcium was analysed with treatment, time (4 time points) and their interaction as fixed effect. Cow was considered the experimental unit and the random effect with time used to model repeated measures using the appropriate (co)variance structure as determined by the lowest Bayesian Information Criterion.

\section{Results}

\subsection{Clinical Milk Fever Risk}

A clinical milk fever case was determined to be any cow that had shown clear clinical signs of milk fever, such as; visibly unsteady on her feet, cold extremities, shivering or unable to rise and stand and had also recorded a blood calcium result below the clinical milk fever threshold $(<1.5$ $\mathrm{mM})$. There were no cases of clinical milk fever within the CSC group, with 3 cases of clinical milk fever reported in the CON group. These cows were successfully treated with an intravenous infusion of calcium borogluconate and subsequently removed from the study. 
Table 2. Clinical Milk Fever Incidence Rate.

\begin{tabular}{lll}
\hline & CON & CSC \\
\hline $\mathrm{n}$ & 19 & 19 \\
Clinical Milk Fever Cases & 3 & 0 \\
Clinical Milk Fever Rate $($ Blood $C a<1.5 \mathrm{mM})$ & $15.7 \%$ & $0 \%$ \\
\hline
\end{tabular}

\subsection{Sub-clinical Milk Fever Risk}

Figure 1 outlines the effect of treatment on blood $\mathrm{Ca}$ concentration. Cows on the CSC treatment had higher blood calcium concentration $(\mathrm{P}<0.01)$ compared to the $\mathrm{CON}$ group. There was no difference in the blood calcium level between the $\mathrm{CSC}$ and $\mathrm{CON}$ at time point 0 , prior to treatment
$(\mathrm{P}=0.95)$. However, the CSC treatment demonstrated higher blood calcium concentrations than the CON treatment at 1, 4 and 8 hours. At hour 1 , the CSC group show a trend $(\mathrm{P}=$ 0.09 ) towards higher blood calcium status when compared to the CON group. The CSC group then demonstrate a significantly higher blood calcium level than the CON group at both 4 hours $(\mathrm{P}=0.01)$ and 8 hours $(\mathrm{P}=0.003)$. The CSC group maintained a blood calcium level above the normocalcaemic threshold $(\mathrm{Ca}>2.0 \mathrm{mM})$ in the first 8 hours after calving. However, by the first hour the blood calcium levels of the CON group fell below the sub-clinical threshold $(\mathrm{Ca}<2.0 \mathrm{mmol} / \mathrm{L})$ and did not recover to normo-calcaemic status by 8 hours post-partum.

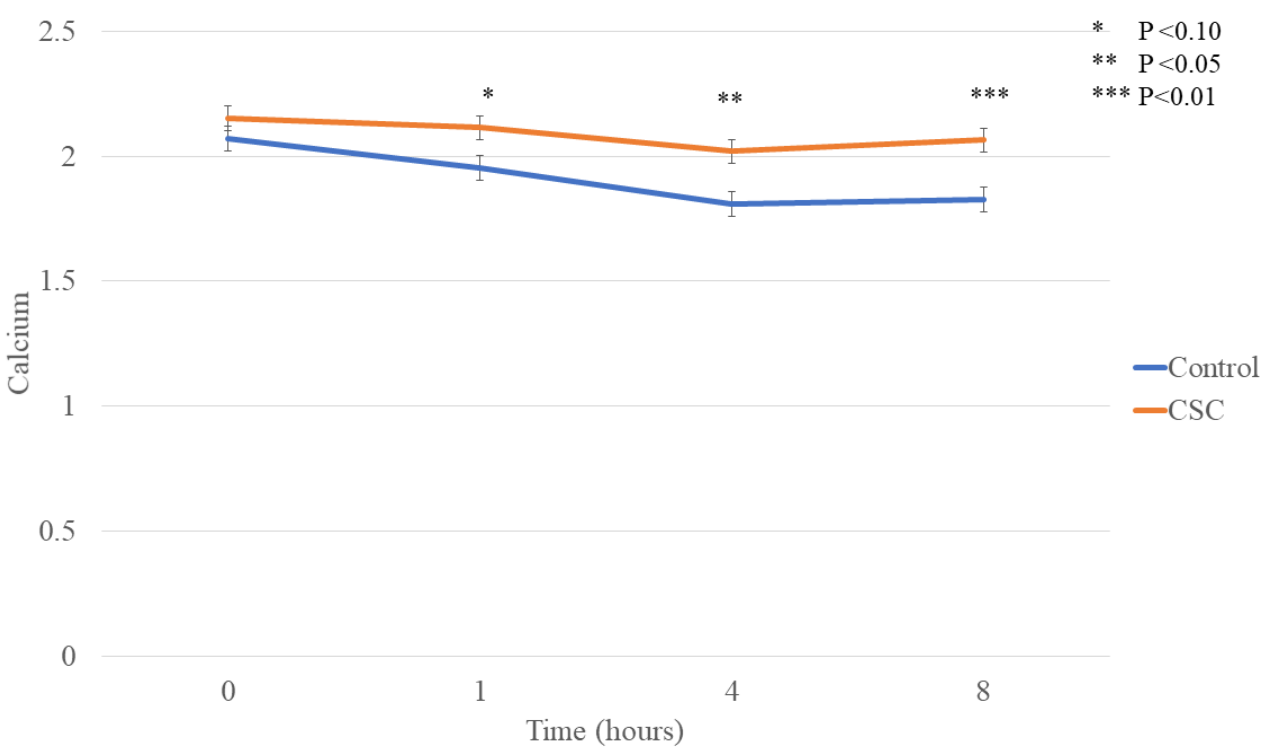

Figure 1. Blood Calcium Results. Least Square Means ( $($ SEM) for the Blood Calcium Levels of Treatment (CSC) and Control Cows with 305 d ECM included as covariate.

The baseline values for the CSC group and the CON group are shown in figure 2. The blood calcium level of the CON group drops by $0.27 \mathrm{mM}$ four hours after calving, this is in comparison to a decrease of $0.12 \mathrm{mM}$ for the CSC group at the same time point.

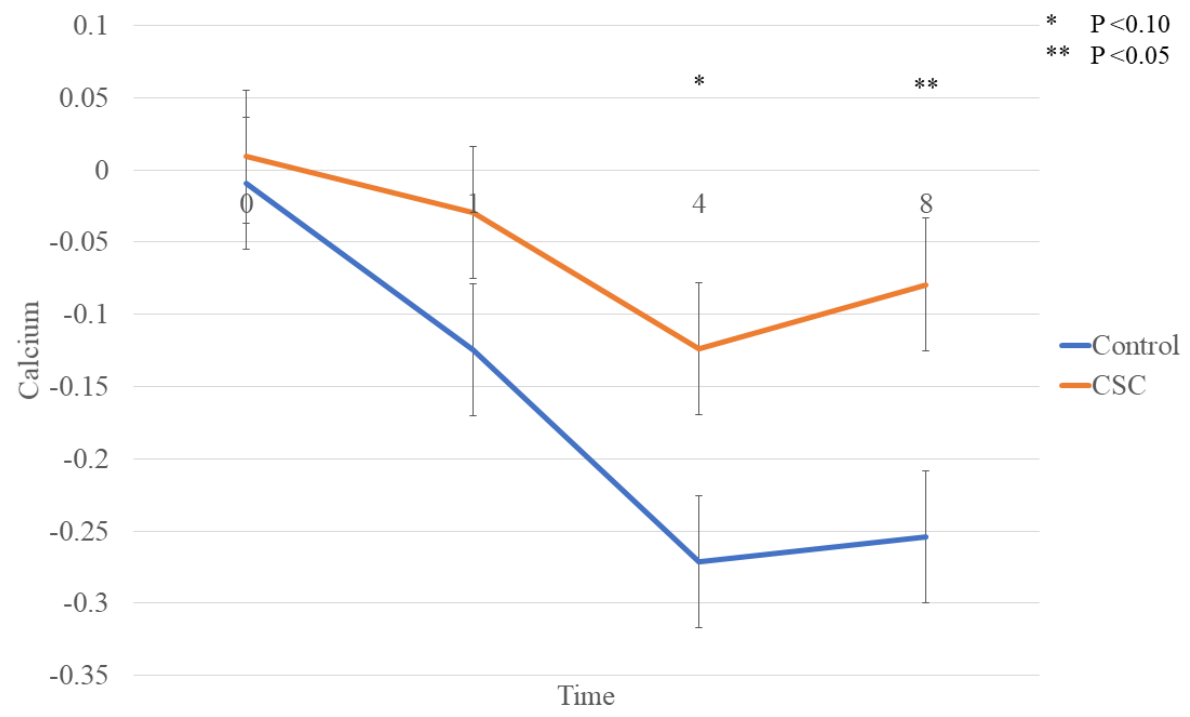

Figure 2. Baseline Value Results. Least Square Means ( \pm SEM) for the Baseline Values of the Treatment (CSC) and the Control Cows. 


\subsection{Milk Production}

A numerical increase in milk volume of $1.7 \mathrm{~kg} /$ day $(\mathrm{P}=$ 0.21) was observed for the CSC group (41.0 kg/day) compared to CON (39.3 kg). However, a statistical trend was observed for Energy Corrected Milk production of $1.8 \mathrm{~kg} /$ day $(\mathrm{P}<0.10)$ for CSC $(45.6 \mathrm{~kg} /$ day $)$ when compared to CON
(43.8 kg/day). There was a significant increase in Milk Fat $\mathrm{Kg}$ production of $+0.10 \mathrm{~kg} /$ day $(\mathrm{P}<0.05)$ for the $\mathrm{CSC}$ group compared to $\mathrm{CON}$ and also a statistical trend of an increase in combined Milk Fat and Protein $\mathrm{Kg}$ of $+0.13 \mathrm{~kg} /$ day $(\mathrm{P}<$ 0.10) for the CSC group compared to $\mathrm{CON}$.

Table 3. Milk Production Records.

\begin{tabular}{|c|c|c|c|c|}
\hline Production Parameters (d5-d60) & CON & CSC & Diff $+/-$ (daily) & P-value \\
\hline Average Daily Milk Production Kg & 39.3 & 41.0 & +1.7 & 0.21 \\
\hline Energy Corrected Milk Volume Kg & 43.8 & 45.6 & +1.8 & 0.10 \\
\hline Fat $\%$ & 3.79 & 3.92 & +0.13 & 0.37 \\
\hline Protein \% & 3.41 & 3.40 & +0.00 & 0.95 \\
\hline Total Fat Kg & 86.0 & 91.9 & +0.10 & 0.05 \\
\hline Total Protein Kg & 77.5 & 79.0 & +0.03 & 0.51 \\
\hline Total Fat + Protein Kg & 163.6 & 170.9 & +0.13 & 0.10 \\
\hline
\end{tabular}

\section{Discussion}

Post-partum calcium supplementation of dairy cows has become an accepted management protocol as dairy farmers become more aware of the negative effects of sub-clinical milk fever in freshly calved cows. Whilst some studies have shown a benefit to calcium supplementation in the general population, to the authors knowledge, none have focused on its benefit in a focused cohort of at-risk, older and higher yielding cows. Previous studies of supplementation with a combined calcium, magnesium and antioxidant bolus (Cow Start) have shown benefits to treatment in terms of fewer metabolic issues, better energy status and higher milk production, when compared to control and calcium only supplement groups [28, 29].

Having an older herd profile can help to improve overall herd profitability as well as reducing the environmental impact of dairy production [1]. Whilst older cows can be some of the most profitable producers on the farm, they can be more prone to early lactation metabolic challenges and at higher risk of culling or death in early lactation $[6,7]$. The trial specifically focused on a cohort of cows within the herd that were older and higher yielding. The selected cows had an above average age of 4.7 lactations at calving, with $40 \%$ of the cows being in their $6^{\text {th }}$ lactation or greater. We consider these cows to be high yielding as their production level of $8,834 \mathrm{~kg}$ in their previous 305 day lactation is $52 \%$ above the Irish national production average of $5,783 \mathrm{~kg}$ [30].

Cows that can maintain normo-calcaemic status $(>2.0$ $\mathrm{mM}$ ) are shown to maintain better energy and immune status and are at a lower risk of culling from the herd or death [8, $13,16]$. The results of this trial show a significant improvement $(\mathrm{P}<0.01)$ in the blood calcium status of the CSC cows over the CON group. The results also show than at all 4 time points the CSC group of cows maintained their blood calcium above the normo-calcaemic threshold of $>2.0$ $\mathrm{mM}$, whereas the CON group were in the sub-clinical range $\leq 1.5 \mathrm{mM}$ and $\geq 2.0 \mathrm{mM})$ within 1 hour of calving $(\mathrm{P}<0.09)$ and remained there at 4 hours $(\mathrm{P}=0.01)$ and 8 hours $(\mathrm{P}=0.003)$ post-partum.

These results also show that the blood $\mathrm{Ca}$ status of the CON group deteriorated by $0.27 \mathrm{mM}$ from $0 \mathrm{~h}$ to nadir at $4 \mathrm{~h}$, compared to a decrease of $0.12 \mathrm{mM}$ for the CSC group $(\mathrm{P}=0.01)$. This result may have a bearing on subsequent uterine recovery performance as Martinez et al. (2012) had previously demonstrated that the relative risk of developing metritis reduces by $22 \%$ for every $0.25 \mathrm{mM}$ increase in blood Ca status, which correlates with results in previous studies of the Cow Start bolus [13, 28, 29]. This result indicates that the CSC group maintain a more favourable $\mathrm{Ca}$ status in the critical hours after calving. The fact that $15.7 \%$ of the CON group had a case of clinical milk fever demonstrates that these cows were indeed in a precarious calcium status.

These results were in line with our initial study hypothesis, and we believe show that the greater specification of the product and availability of the calcium therein was able to deliver an improved calcium status in the critical hours postpartum. Our research group has concluded that to better understand the wider implications of this supplementation strategy in older, at-risk cows that future studies should include larger populations of cows spread across numerous herds. We also feel there would be a benefit to studying in greater detail the effect and potential benefit to various postpartum supplementation strategies on the dry matter intakes of this cohort of cows.

The results from this study show an improvement in energy corrected milk production volumes for the CSC group compared to the CON group $(+1.8 \mathrm{~kg} /$ day, $\mathrm{P}<0.10)$. This increase in milk volume is also accompanied by an increase in milk fat $(\mathrm{P}<0.05)$ and combined milk fat and protein $\mathrm{kg}(\mathrm{P}$ $<0.10)$. This combination of higher milk volume and milk fat may be an indication that the CSC group of cows are in better metabolic energy status. This improved energy status was reported in previous studies of cows receiving the Cow Start bolus demonstrating better energy status in early lactation by means of a better body condition score profile $(\mathrm{P}<0.07)$, less body weight loss (numerical observation) and a significant 
reduction in circulating ketone levels (Beta-Hydroxy Butyric Acid) indicating a lower level of body fat lipomobilisation ( $\mathrm{P}$ $<0.01)$. [28, 29]

\section{Conclusions}

The results of this trial demonstrate that the prophylactic treatment of a group of at risk, freshly calved, older and higher yielding cows with two oral combined calcium, magnesium and antioxidant (Cow Start) boluses had a beneficial effect on early lactation calcium status as indicated by significantly higher blood calcium status in the critical hours post- partum. Furthermore, the intervention resulted in an increase in energy corrected milk, milk fat and combined milk fat and protein production over the first 60 days into lactation. These results indicate that the Cow Start intervention reduced the risk of clinical milk fever and maintained blood Ca status above the sub-clinical milk fever threshold in the critical hours after calving which can have longer lasting benefits during lactation, specifically in terms of energy corrected milk production, a benefit which was not seen in the control group of cows in this study.

\section{Acknowledgements}

The authors would like to acknowledge the cooperation and efforts of the owners and staff at the participating dairy farm and their veterinary surgeon for providing access to their records and farm data and for initiating this research.

\section{References}

[1] F. Grandl, M. Furger, M. Kreuzer, and M. Zehetmeier, "Impact of longevity on greenhouse gas emissions and profitability of individual dairy cows analysed with different system boundaries". Animal, vol. 13: 1, pp 198-208, 2019.

[2] I. Komlósi, M. Wolfová, J. Wolf, B. Farkas, Z. Szendrei, Z. and B. Béri, "Economic weights of production and functional traits for Holstein-Friesian cattle in Hungary". J. Anim. Breed. Genet., vol. 127, 143-153, 2010.

[3] FAO, 2013. Available at http://faostat.fao.org/site/569/DesktopDefault.aspx?PageID=5 69\#ancor

[4] A. C. Boulton, J. Rushton, and D. C. Wathes, "An empirical analysis of the cost of rearing dairy heifers from birth to first calving and the time taken to repay these costs". Animal vol. 11, 1372-1380, 2017.

[5] D. Pellerin, S. Adams, F. Bécotte, R. Cue, R. Moore, and R. Roy, "Pour une vache, l'âge d'or c'est la 4e lactation" In In Proceedings of the Symposium sur les Bovins Laitiers: Choix D'aujourd'hui Pour les Défis de Demain, CRAAQ - Le Centre de Référence en Agriculture et Agroalimentaire du Québec, Saint-Hyacinthe, QC, Canada, 5 November 2014; pp. 133-147.

[6] H. A. Seifi, S. J. LeBlanc, K. E. Leslie and T. F. Duffield, "Metabolic predictors of postpartum disease and culling risk in dairy cattle". The Veterinary Journal vol. 188, 216-220, 2011.
[7] J. P. Goff, 'The monitoring, prevention, and treatment of milk fever and subclinical hypocalcemia in dairy cows', The Veterinary Journal, vol. 176, no. 1, pp. 50-57, 2008, https://doi.org/10.1016/j.tvj1.2007.12.020

[8] T. A. Reinhardt, J. D. Lippolis, B. J. McCluskey, J. P. Goff, and R. L. Horst, 'Prevalence of subclinical hypocalcemia in dairy herds,' The Veterinary Journal, vol. 188, no. 1, pp. 122 124, 2011, https://doi.org/10.1016/j.tvj1.2010.03.025

[9] M. Probo, O. B. Pascottini, S. LeBlanc, G. Opsomer, and M. Hostens, "Association between metabolic diseases and the culling risk of high-yielding dairy cows in a transition management facility using survival and decision tree analysis," Journal of Dairy Science vol. 101, 9419-9429, 2018.

[10] R. L. Horst, J. P. Goff, and T. A. Reinhardt, 'Adapting to the Transition Between Gestation and Lactation: Differences Between Rat, Human and Dairy Cow', Journal of Mammary Gland Biology and Neoplasia, vol. 10, no. 2, pp. 141-156, 2005.

[11] P. J. De Garis, I. J. Lean, 'Milk fever in dairy cows: A review of pathophysiology and control principles', The Veterinary Journal, vol. 176, no. 1, pp. 58 - 69, 2008, https://doi.org/10.1016/j.tvj1.2007.12.029

[12] F. Mulligan, L. O'Grady, D. Rice, and M. Doherty, 'Production diseases of the transition cow: Milk fever and subclinical hypocalcaemia', Irish Veterinary Journal, vol. 59, no. 12 , pp. $697-701,2006$.

[13] N. Martinez, C. A. Risco, F. S. Lima, R. S. Bisinotto, L. F. Grego, E. S. Riberio, F. Maunsell, K. Galvao, and J. E. P. Santos. "Evaluation of peripartal calcium status, energetic profile, and neutrophil function in dairy cows at low or high risk of developing uterine disease," J. Dairy Sci. vol. 95: 7158-7172, 2012, doi: 10.3168/jds.2012-5812.

[14] R. J. Jorgenson, N. R. Nyengaard, S. Hara, J. M. Enemark and P. H. Andersen 'Rumen motility during induced hyper- and hypocalcaemia'. Acta. Vet. Scand. Vol 39: 331-338, 1998.

[15] T. Y. Ma, D. Tran, N. Hoa, D. Nguyen, M. Merryfield and A. Tarnawski, 'Mechanism of Extracellular Calcium Regulation of Intestinal Epithelial Tight Junction Permeability: Role of Cytoskeletal Involvement'. Microscopy Research and Technique vol 51, 156-168, 2000.

[16] K. Kimura, T. A. Reinhardt, and J. P. Goff, 'Parturition and hypocalcemia blunts calcium signals in immune cells of dairy cattle', Journal of dairy science, vol. 89, no. 7, pp. 2588-2595, 2006, https://doi.org/10.3168/jds.S0022-0302(06)72335-9

[17] L. C. Whiteford, and I. M. Sheldon, "Association between clinical hypocalcaemia and postpartum endometritis," The Veterinary Record vol. 157, 202-204, 2005.

[18] R. K. Rude, S. B. Oldham, C. F. Sharp Jr., and F. R. Singer, "Parathyroid Hormone Secretion in Magnesium Deficiency*," J. Clin. Endocrinol. Metab., vol. 47, no. 4, pp. 800-806, Oct. 1978, doi: 10.1210/jcem-47-4-800.

[19] E. T. Littledike, J. A. Stuedemann, S. R. Wilkinson, and R. L. Horst, "Grass Tetany Syndrome," in Proc. John Lee Pratt Int. Symp. Role Magnes. Anim. Nutr, Virginia Polytechnic Institute and State University, p. 173, 1983.

[20] S. J. LeBlanc, et al., 'Peripartum serum vitamin E, retinol, and beta-carotene in dairy cattle and their associations with disease', J Dairy Sci, 2004. 87 (3): p. 609-19, 2004. 
[21] C. K. Cebra, et al., The relationship between endogenous cortisol, blood micronutrients, and neutrophil function in postparturient Holstein cows, $J$ Vet Intern Med, vol. 17 (6): p. 902-7, 2003.

[22] J. W. Spears, and W. P. Weiss, Role of antioxidants and trace elements in health and immunity of transition dairy cows, Vet $J, 176$ (1): p. 70-6, 2008.

[23] Hogan, J. S., et al., Bovine neutrophil responses to parenteral vitamin E. J Dairy Sci, 75 (2): p. 399-405, 1992.

[24] G. R. Oetzel, and B. E. Miller. 2012. "Effect of oral calcium bolus supplementation on early-lactation health and milk yield in commercial dairy herds," J. Dairy Sci. vol. 95: 7051-7065, 2012, doi.org/10.3168/ jds.2012-5510.

[25] J. A. A. McArt, and G. R. Oetzel, "A stochastic estimate of the economic impact of oral calcium supplementation in post parturient cows," Journal of Dairy Science vol. 98: 74087418, 2015, doi.org/10.3168/jds.2015-9479.

[26] A. Valldacabres, J. A. A. Pires, and N. Silva-del-Rio, "Effect of prophylactic oral calcium supplementation on postpartum mineral status and markers of energy balance of multiparous Jersey cows," J. Dairy Sci. vol. 101: 4460-4472, 2018, doi.org/10.3168/jds.2017-12917.

[27] B. M. Leno, R. C. Neves, I. M. Louge, M. D. Curler, M. J. Thomas, T. R. Overton, and J. A. A. McArt. "Differential effects of a single dose of oral calcium based on postpartum plasma calcium concentration in Holstein cows," J. Dairy Sci. vol. 101: 3285-3302, 2018, doi.org/10.3168/jds.2017-13164.

[28] J. Lawlor, A. Fahey, E. Neville, A. Stack, and F. Mulligan, "On-farm Safety and Efficacy Trial of Cow Start Calcium Bolus," Anim. Vet. Sci., vol. 7, no. 6, pp. 121-126, 2019, doi: 10.11648/j.avs.20190706.11.

[29] Lawlor, J., Fahey, A., Neville, E., Stack, A., and Mulligan, F. "Effect of Cow Start Calcium Bolus on <etabolic Status and Milk Production in Early Lactation," Anim Vet Sci., vol. 8, no. 6, pp. 124-132, 2020, doi: 10.11648/j.avs.20200806.12.

[30] European Commission, Milk and Dairy Products, information on production, accessed on Aug $18^{\text {th }} 2021$, available at https://ec.europa.eu/info/sites/default/files/food-farmingfisheries/farming/documents/eu-milk-yield-herds_en.pdf 